\title{
Mindfulness Training with Deepbreathing Techniques to Increase Disability Resilience
}

\author{
Nurhaeda Nurhaeda ${ }^{1}$, Anwar Sutoyo $^{2}$, Mulawarman Mulawarman $^{3}$ \\ \{aidhanur130@gmail.com ${ }^{1}$, mulawarman@mail.unnes.ac.id ${ }^{2}$, anwarsutoyo@mail.unnes.ac.id ${ }^{3}$ \}
}

Universitas Negeri Semarang, Indonesia ${ }^{1,2,3}$

\begin{abstract}
Resilience is a capacity of individual to adapt positively when faced an adversity which is high risk of prolonged crisises. Facilitating the focus and process of awareness is very important in increasing resilience to students with disabilities, because low resilience in students with disabilities has consequences for their future. The purpose of the study is to analyze effectiveness of mindfulness training with deepbreathing techniques in increasing resilience of disability students. This research methodology used quantitative with quasi-experimental pre-test post-test control group design, data collection techniques carried out by psychology scale, data analysis consists of descriptive analysis by looking at the mean and standard deviation (SD) and hypothesis testing in this study using nonparametric statistical methods with Wilcoxon sign rank test. The results showed that mindfulness training with deepbreathing techniques effective to increasie resilience in students with disabilities.
\end{abstract}

Keywords: Resilience, disability, mindfulness, deepbreathing.

\section{Introduction}

Individual development is a change that continues. Success in achieving a stage of development will greatly determine success in the next stage of development. Conversely, if there is one development process that is hampered, disrupted, or even decapitated and then left behind, then it is difficult to achieve optimal development and even affect learning ability. Disability students experience barriers, disturbances, slowness that have the potential for low resilience (Schonenberg, et al., 2014), and in general, it has been proven by the findings of research conducted by Graff (2013) that students who belong to the minority group have a low level of resilience.These risk factors that if they do not get the right intervention according to their specific needs, can develop into a permanent one.

The explanation above in accordance with Engel, et al., (2013) states that disability children often have negative thoughts related to their limitations, consider themselves as people who fail due to weaknesses or deficiencies in their physical. These pressures reflect substantial and high-risk difficulties, or have the potential to create prolonged crises in students with disabilities that they cannot easily overcome themselves. Based on the opinions above, students with disabilities must be able to build resilience in themselves in order to adapt positively without raising pathological symptoms (Overcoming, steering through, bounce back, and reaching Out).

Reivich \& Shatte 2002 (in Reivich, et al., 2013), resilience is the ability of individuals to adapt positively when faced with adversity or trauma experienced in their lives, mentions that 
there are seven aspects of resilience capabilities: emotional regulation, impulse control, optimism, causal analysis, empathy, self efficacy and reaching out. Ungar \& Lienberg (in Anghel, 2015) resilience or personality ability to persist as a general concept involves interaction between individuals, the experience of the masses, family and community resources. Basically, as research conducted by Schonenberg, et al., (2014), shows that persons with disabilities have low resilience. However, resilience is not seen as a definite attribute and is not an innate attribute but is a dynamic process that develops over time (Wagstaff, et al., 2016). Resilience is more accurate if seen as part of the development of mental health in a person that can be improved in a person's life cycle.

Guidance and development counseling provides assistance designed by focusing on needs, strengths, interests, and issues related to the stages of child development and is the most important and integral part of the overall education program (Myrick, 2011). School counselors are expected to provide fair services to all students, including providing appropriate services for students with disabilities (Geddes Hall, 2015; Nava \& Gragg, 2015). Providing fair services to all students as part of a comprehensive counseling program is how the strategy helps disabled students achieve self-integrity in all aspects (Buckley, 2018). In this case, for assistance efforts to students with disabilities a counselor are expected to have the capacity for special interventions, counselors must look for other approaches that are more efficient and effective (Charlesworth \& Jakson in Mulawarman, 2014).

There are several approaches to guidance and counseling, one of which is mindfulness. The mindfulness approach that is centered on consciousness and with non-judgmental attitudes and judgments can be transferred meaningfully to various cultural contexts, including the context of gender, race, ethnicity, socio-economic, disability and sexual orientation. According to Bogels (2013) what is processed in mindfulness is to get rid of thoughts that make people unaware of what is happening. The deepbreathing technique of the mindfulness approach is based on the concept of yoga Hindu philosophers believe that by being able to control their breathing, a person is considered capable of controlling his life energy (Erford, 2016).

The literature review reveals the relationship between mindfulness and resilience. Some results of these studies such as: [1] Jha et al,. (2010) that mindfulness training shows potential as an effective intervention to increase resilience in individuals at risk of psychological trauma; [2] Chavers (2013) found that there was a significant correlation between mindfulness and resilience, where the position of mindfulness was a significant predictor of resilience; [3] Foureur et al,. (2013) that mindfulness is an antecedent to resielience; [4] Keye \& Pidgeon (2013) found that mindfulness is a significant predictor of resilience; [5] Bajaj \& Pande (2016) also revealed that individuals with higher mindfulness have greater resilience, because the mechanism of mindfulness is a potential mediator that underlies resilience.

Related research results by: [1] Singh, et al,. (2013) The results demonstrate the effectiveness of the mindfulness-based procedure for assisting individuals with mild intellectual disabilities to control their physical and verbal aggression. [2] Singh, et al,. (2011) These findings suggest that individuals with mild ID, who have mastered an effective mindfulness-based strategy to control their aggressive behavior. [3] Chilvers (2011) In this study the practice of mindfulness was introduced to a medium secure ward for female patients with learning disabilities in the form of twice-weekly, 30 minute group sessions, mindfulness practice sessions in reducing aggression is discussed.

Even so, there has never been a previous study that examines increasing disability resilience by using mindfulness training with deepbreathing techniques in counseling. There is also the purpose of this study is to test the effectiveness of the 'deep and slow breathing' skills 
on the mindfulness approach as one of the strategies that can improve the skills of students with disabilities to realize all physical and psychological reactions experienced from time to time.

\section{Methods}

This research method is quantitative with quasi experiment pre-test post-test control group design. Participants $(\mathrm{N}=14)$ have low and moderate resilience, data obtained from psychological scale measurements developed from the characteristics of resilience in the theory of Reivich \& Shatte (2002) consisting of seven aspects: emotions regulations, impulse control, optimism, casual analysis, empathy, self-efficacy, reaching out. Each aspect is further divided into two indicators and further elaborated in the form of instrument items by rating the Likert model scale with weights values sequentially $1-4$. Participants $(\mathrm{N}=12)$ were divided into two experimental groups, the treated group and the control group, both groups were measured on a pre-test and post-test resilience scale. This experimental research consisted of 6 meetings over 3 weeks, in one week 2 meetings were held which lasted 45 minutes. Before entering the training phase, researchers first filled out the observation scale (Pre-test). In the first stage the formation of training groups (group exercise), and the practice phase of the present experience, in the second stage of body scanning, the stage of acceptance. The three stages of treatment were given using the roleplay method for 4 consecutive times, the participants were trained in a sitting position in all sessions. At each meeting using LCD aids and assisted by a co.leader of bisindo teachers. Furthermore, the latter filled the observation scale (Post-test) and the assignment for independent practice. Researchers assisted by co. Eksprimentor is a sign language teacher with 35 years of experience teaching at SLB.

Researchers used descriptive analysis by looking at the mean (mean) and Standard Deviation (SD) with the help of SPSS to find empirical data about the level of resilience before and after treatment given mindfulness training with deepbreating techniques so that it can be seen how much mindfulness training can increase resilience.

Hypothesis testing in this study uses nonparametric statistical methods with the Wilcoxon sign rank test.

\section{Results and Discussion}

Based on the results of the research that has been carried out, data analysis results will be described on the level of resilience of Ungaran State SLB students both before (pre-test) and after intervention (post test), and hypothesis testing (Wilcoxon analysis) to see the effect of mindfulness training in increasing resilience.

The effect of mindfulness training in increasing the resilience of students with disabilities using:

\subsection{Quantitative descriptive analysis}

In this research quantitative descriptive analysis is used through the calculation of the mean (mean) and standard deviation (SD). This analysis is used to see the level of resilience of students with disabilities before (pre-test) and after (post-test) intervention is given. 
Tabel 1. Resilience of pre-test and post-test experiment groups

\begin{tabular}{llcccr}
\hline & N & Mean & Std. Deviation & Minimun & Maximum \\
\hline Pre_Test & 7 & 97,7143 & 7,63139 & 87,00 & 109,00 \\
Post_Test & 7 & 120,4286 & 4,72077 & 110,00 & 124,00 \\
\hline
\end{tabular}

Tabel 2. Resilience of pre-test and post-test control groups

\begin{tabular}{llcccr}
\hline & N & Mean & Std. Deviation & Minimun & Maximum \\
\hline Pre_Test & 7 & 91,8571 & 9,42388 & 75,00 & 105,00 \\
Post_Test & 7 & 103.4286 & 2,69921 & 99,00 & 108,00 \\
\hline
\end{tabular}

\subsection{Hypothesis testing with wilcoxon analysis}

In this Researcher uses wilcoxon sign rank test to test the effectiveness of mindfulness training interventions with deepbreating techniques to increase resilience in students at SLB Negeri Ungaran.

Tabel 3. Resilience of the pre-test and post-test experiment groups

Tabel 3.1. Wilcoxon Signed Ranks Test

\begin{tabular}{llccc}
\hline & & N & Mean Rank & Sum of Ranks \\
\hline Pre_Test - Post_Test & Negative Ranks & $7^{\mathrm{a}}$ & 4,00 & 28,00 \\
& Positive Ranks & $0^{\mathrm{b}}$ &, 00 &, 00 \\
& Ties & $0^{\mathrm{c}}$ & & \\
& Total & 7 & & \\
\hline
\end{tabular}

Tabel 3.2. Based on positive ranks.

\begin{tabular}{lr}
\hline \multicolumn{2}{c}{ Pre_Test - Post_Test } \\
\hline Z & $-2,366^{\mathrm{b}}$ \\
Asymp. Sig. (2-tailed) &, 018 \\
\hline
\end{tabular}

Based on the output test statistics above, it is known Asymp.Sig. (2-tialed) value of 0.018 $>0.05$, it can be concluded that $\mathrm{Ha}$ is accepted, meaning that there are differences between the experiment group before and after treatment so that it can be concluded also that: Mindfulness with deepbreating techniques is effective to increase resilience.

Tabel 4. Resilience of the pre-test and post-test control groups

Tabel 4.1. Wilcoxon Signed Ranks Test

\begin{tabular}{llccc}
\hline & & N & Mean Rank & Sum of Ranks \\
\hline Pre_Test - Post_Test & Negative Ranks & $6^{\text {a }}$ & 4,50 & 27,00 \\
& Positive Ranks & $1^{\text {b }}$ & 1,00 & 1,00 \\
& Ties & $0^{\text {c }}$ & & \\
\hline
\end{tabular}


Tabel 4.2. Based on positive ranks.

\begin{tabular}{lr}
\hline \multicolumn{2}{c}{ Pre_Test - Post_Test } \\
\hline $\mathrm{Z}$ & $-2,197^{\mathrm{b}}$ \\
Asymp. Sig. (2-tailed) &, 028 \\
\hline
\end{tabular}

Based on the Test Statistics output above, note Asymp.Sig. (2-tialed) value of $0.028>$ 0.05 , it can be concluded that $\mathrm{Ha}$ is accepted, meaning that there are differences between the control groups before and after treatment so that it can be concluded also that: Mindfulness with deepbreating techniques is effective to increase resilience.

\section{Implications}

The implications of this research are: [1] As a complement in scientific guidance and counseling intervention specifically for students with disabilities. [2] The use of simple interventions tailored to the conditions and cognitive abilities of students with disabilities in achieving counseling goals. The thing to note is the planning, development and training so that they can provide tangible skills for students with disabilities.

\section{Conclusion}

Based on the analysis of the above research data, it can be concluded that mindfulness training with deepbreating techniques is effective for increase resilience of students with disabilities, there are differences between the experimental group before (pre-test) and after (pre-test) the intervention is given with Asymp. (2-tialed) value of 0.018>0.05. 


\section{References}

[1] Anghel, R. E.: Psychological And Educational Resilience In High vs. Low-Risk Romanian Adolescents. Vol. 203, pp.153-157. Procedia Social and Behavioral Sciences. International Conference Education And Psychology Challenges - Teachers For The Knowledge Society - 3rd Edition, Epc-Tks (2015).

[2] Bajaj, B., \& Pande, N.: Mediating role of resilience in the impact of mindfulness on life satisfaction and affect as indices of subjective well-being. Vol. 93, pp. 63-67. Personality and Individual Differences (2016).

[3] Buckley, M., \& Mahdavi, J. N.: Bringing Children from the Margins to the Page: School Counselors Supporting Students with Learning Disabilities. Vol. pp. 16: 23. (2018).

[4] Bogels, s. M., \& Hellemans, J.: Mindful Parenting In Mental Health Care: Effects On Parental And Child Psychopathology, Parental Stress, Parenting, Coparenting, And Marital Functioning. Vol. 5, pp. 536-551. Springer Journal of Mindfullness. (2013).

[5] Chavers, D. J.: Relationships between spirituality, religiosity, mindfulness, personality, and resilience. Doctoral Dissertation, Ala- bama: University of South Alabama. (2013).

[6] Chilvers, Thomas \&Stanbury,:The impact of a ward-based mindfulness programme on recorded aggression in a medium secure facility for women with learning disabilities, Journal of Learning Disabilities and Offending Behaviour. Vol. 2, pp. 27-41.(2011).

[7] Engel, J. M., Wilson, S., Tran, S. T., Jensen, M. P., \& Ciol, M. A.: Pain catastrophizing in youths with physical disabilities and chronic pain. Vol.38, pp. 192-201. Journal of Pediatric Psychology. (2013).

[8] Erford B.: 40 Teknik Yang Harus Dikuasai Konselor. Edisi Ke Dua. Yogyakarta: Pustaka Pelajar. (2016)

[9] Foureur, Besley, Burton, Yu, \& Crisp.: Enhancing The Resilience Of Nurses And Midwives: Pilot Of A Mindfulnessbased Program For Increased Health, Sense Of Coherence And Decreased Depression, Anxiety And Stress. Vol. 45. Journal Contemporary Nurse. (2013).

[10] Geddes Hall, J.: The school counselor and special education: Aligning training with practice. Vol. 5, pp. 217-224. The Professional Counselor (2015).

[11] Graff, C.S.: Latina Resilience in Higher Education: Contributing Factors Including Seasonal Farmworker Experiences. Vol.12 (4), 334-344. Journal of Hispanic Higher Education. (2013).

[12] Jha, A. P., Stanley, E. A., Kiyonaga, A., Wong, L., \& Gelfand, L.: Examining the protective effects of mindfulness training on working memory capacity and affective experience. Vol.10 (1), 54. Emotion. (2010).

[13] Keye, M. D., \& Pidgeon, A. M.: Investigation of the relationship between resilience, mindfulness, and academic self-efficacy. Vol. 1, pp.1. Journal of Social Sciences. (2013).

[14] Myrick, Robert D.: Developmental Guidance and Counseling : A Practical Approach Fifth edition. Minneapolis : Educational Media Corporation. (2011).

[15] Mulawarman: Brief Counseling in Schools: A Solution Focused Brief Counseling Approach For School Counselor In Indonesia.. Vol. 5. Journal Of Education And Practice. (2014).

[16] Nava, Y., \& Gragg, J. B.: School counselors' perceptions of preparedness in advocating for special education students. Vol. 1, pp. 5-24. The South Carolina Counseling Forum. (2015).

[17] Reivich, K., Gillham, J. E., Chaplin, T. M., \& Seligman, M. E.: From helplessness to optimism: The role of resilience in treating and preventing depression in youth. In Handbook of resilience in children (pp. 201-214). Springer, Boston, MA. (2013).

[18] Schonenberg et al,.: Depression, Posttraumatic Stress, and Risk Factors Following Spinal Cord Injury. Vol. 21. International Journal of Behavioral Medicine. (2014).

[19] Singh, N. N.,et al,.: Mindfulness-based treatment of aggression in individuals with mild intellectual disabilities: a waiting list control study. Mindfulness. Vol. 4, pp. 158-167. (2013).

[20] Singh, Lancioni \& Winton: Peer with intellectual disabilities as a mindfulness-based anger and aggression management therapist. Vol. 32, pp. 2697-2703.(2011). 
[21] Wagstaff ed.: Resilience In Sport: A Critical Review Of Psychological Processes, Sociocultural Influences, And Organizational Dynamics. The organizational psychology of sport: key issues and practical applications, London: routledge. (2016). 